\title{
Detection of Trichoderma aggressivum in bulk phase III substrate and the effect of $T$. aggressivum inoculum, supplementation and substrate-mixing on Agaricus bisporus yields
}

\author{
Matthew O'Brien • Kevin Kavanagh • Helen Grogan
}

Accepted: 20 June 2016 / Published online: 27 June 2016

(C) Koninklijke Nederlandse Planteziektenkundige Vereniging 2016 depending on the experiment and the inoculum dilution level, and false negatives $(\mathrm{CT}=40)$ were reported on one occasion with the most dilute samples. The results indicate that Phase III mushroom substrate is vulnerable to infection by $T$. aggressivum when the fully colonised substrate is broken up and mixed during bulk handling operations, identifying a previously unidentified risk for Phase III substrate producers.

Keywords Mushroom compost · Green mould · Phase $3 \cdot$ Detection methods $\cdot$ qPCR $\cdot$ RT-PCR

\section{Introduction}

Compost Green Mould Disease occurs in mushroom crops when fast-growing filamentous fungi of the genus Trichoderma colonize the substrate on which the mushroom mycelium grows (Samuels et al. 2002; Largeteau et al. 2010). In Agaricus bisporus cultivation the most significant Trichoderma species is Trichoderma aggressivum which colonizes mushroom substrate more readily than other Trichoderma species and can cause severe or complete crop loss. This species was first identified in Ireland in the 1980s and has since occurred throughout Europe, the Americas and South Africa although it has not been reported to date from China, Australia or New Zealand. It has been divided into two subspecies, T. aggressivum $\mathrm{f}$. europaeum and T. aggressivum f. aggressivum found in Europe and North America, respectively (Seaby 1987; Chen et al. 1999). 
Exclusionary methods and rigorous hygiene are employed on mushroom farms and substrate facilities to prevent entry and spread of Trichoderma in the production system (Rinker and Alm 2000). Chemical control of T. aggressivum is possible with benzimidazole based fungicides (Grogan et al. 1996; Rinker and Alm 2008) but in many European countries their use is no longer approved to control mushroom pathogens while in North America their use is curtailed due to the development of resistance (Romaine et al. 2008). When T. aggressivum is identified in a mushroom crop the typical outcome is for the crop to be destroyed with steam and discarded immediately to prevent recurrence of infection (Fletcher and Gaze 2008).

When T. aggressivum first occurred in Europe it was associated with in-situ spawn-run systems which consisted of an A. bisporus culture (spawn) being added to pasteurized (Phase II) mushroom substrate that was then filled into bags or blocks and placed in growing rooms, where colonization of the substrate took place in situ. When fully colonized, the substrate was covered with a peat-based layer (casing) and induced to form sporophores. In this system the spawning operation was identified as a critical time for Trichoderma infection, as the readily available carbohydrates present in the spawn grains could give T. aggressivum a foothold from which to colonize the substrate (Fletcher 1997; Seaby 1996). When compost was infected with T. aggressivum at spawning time, sporulating Trichoderma was often visible throughout individual bags or blocks by casing or cropping time, and those units showing symptoms could be selectively destroyed (Beyer et al. 2000). Infection after spawn run was considered less important as compost that was fully colonized by A. bisporus in situ was considered to be more resistant to T. aggressivum infection and there was limited access to the substrate after spawning which meant subsequent infections tended to be limited to the edges of the compost block or bag (Fletcher 1997; Rinker and Alm 2000). However, where a T. aggressivum-contaminated bag or block of substrate was inadvertently used in the preparation of the casing as casing inoculum (cac-ing), then an otherwise healthy crop could also be wiped out.

The use of the Bulk Phase III system for mushroom production has become prevalent in Europe over the past two decades. In this system the substrate is inoculated with a pure culture of $A$. bisporus (spawn) and then incubated (spawn-run) in large tunnels (80-200 t) under stringent hygiene and environmental conditions. There was a marked decrease in the occurrence of Compost Green Mould Disease in Europe with the introduction of this system, which was attributed to improved consistency of substrate, as well as improved exclusion and hygiene during the spawning process that minimized Trichoderma infection at spawning. More recently T. aggressivum infections have occurred sporadically in Bulk Phase III substrate but there is little epidemiological information available in relation to T. aggressivum in bulk systems (Lemmers 2010).

Bulk handling is a key difference between the Bulk Phase III and in-situ spawn run systems. Bulk Phase III substrate is emptied from tunnels by winches and conveyors and filled into transport vehicles for dispatch to growers, where the substrate must again be emptied from the vehicle and filled by conveyors onto shelves in growing rooms (Anon. 2016a; Anon. 2016b). Thus the substrate becomes friable and the handling and filling equipment is designed to ensure that it is well mixed by the time it is on the shelf in a growing room so as to ensure that individual batches of substrate are as 'homogeneous' as possible. There is currently no information on how the bulk handling and mixing operations may affect $T$. aggressivum infection. In this study the effect of incorporating $T$. aggressivum inoculum at different rates into fully colonised bulk handled spawn-run mushroom substrate was investigated. The effect of adding a nutritional supplement to the substrate prior to filling into growing rooms was also investigated as the additional available nutrients may facilitate the growth of $\mathrm{T}$. aggressivum in the substrate. Finally, four methods of detecting T. aggressivum in bulk handled substrates were evaluated to determine if the organism can be readily detected when diluted throughout a mass of substrate.

\section{Materials and methods}

Fungal strains

In each cropping trial the $A$. bisporus spawn strain used was Sylvan A15 (http://www.sylvaninc.com/products. html) and the T. aggressivum f. europaeum isolate used was FM10 (CSL Reference No. 20,802,812, provided by Dr. Charles Lane, Fera, UK) originally obtained from an infected crop in the England, UK in 2008. 
Preparation of inoculum

Phase II mushroom substrate was inoculated with T. aggressivum conidia on spawn grains at spawning time. Six grains were coated with $\sim 10^{6}$ T. aggressivum conidia per grain and added to $18 \mathrm{~kg}$ Phase II mushroom substrate, along with fresh spawn at a rate of $0.05 \%$. The substrate was filled into crates, covered and incubated under standard spawn-run conditions $\left(25^{\circ} \mathrm{C}\right.$ and $95 \% \mathrm{RH}$ ) at the Teagasc Experimental Mushroom Unit to produce Phase III substrate which was heavily colonised by $T$. aggressivum. This infected substrate was used as inoculum in subsequent experiments. At the end of spawn-run, the inoculum was thoroughly mixed by hand to ensure an even distribution of T. aggressivum within the substrate and samples were taken to quantify the initial level of $T$. aggressivum colonisation in terms of colony forming units per gram inoculum ( $\mathrm{cfu} \mathrm{g}^{-1}$ ). Infected substrate inoculum was prepared separately for each cropping trial.

Inoculum addition to bulk phase III substrate

Inoculum prepared above was added to uninfected Bulk Phase III mushroom substrate at four rates: $100 \mathrm{~g} / \mathrm{kg}$, $10 \mathrm{~g} / \mathrm{kg}, 1 \mathrm{~g} / \mathrm{kg}$ and $0.1 \mathrm{~g} / \mathrm{kg}$ (weight inoculum/weight healthy substrate), equivalent to a dilution level of $10^{-1}$, $10^{-2}, 10^{-3}, 10^{-4}$ infected substrate by weight. A control treatment of uninfected Phase III substrate was also prepared.

Three experimental trials were conducted: Trial 1 examined the effect of inoculum dilution level and supplementation on mushroom yield in conjunction with a low level of substrate mixing and Trial 2 examined the effect of inoculum dilution level and supplementation on mushroom yield in conjunction with a high level of substrate mixing. Trial 3 was a repeat of Trials 1 and 2 to confirm the effects of inoculum dilution level and mixing level on mushroom yield but it excluded the supplementation treatment.

\section{Supplementation treatments}

Trials 1 and 2 included two supplementation treatments (supplemented and unsupplemented with $0.75 \% \mathrm{w} / \mathrm{w}$ Nutrigain Natural Gold granules (http://www.nutrigain. $\mathrm{com} /$ ). Supplement was added to the Phase III substrate prior to the inoculation and mixing treatments.
Mixing treatments

The low level of substrate mixing treatment in Trial 1 consisted of the following: a base layer of approximately $25 \%$ of the total volume of Phase III substrate was added to the container, Trichoderma-infected substrate (0.1-100 $\mathrm{g} \mathrm{kg}^{-1}$ ) was gently mixed through the base layer and the remainder of the Phase III was filled into the container with no further mixing. The high level of substrate mixing in Trials 2 and 3 consisted of the following: prior to filling the containers, healthy Phase III substrate was weighed, supplemented as required, and spread out onto a polyethylene sheet, Trichoderma-infected substrate $\left(0.1-100 \mathrm{~g} \mathrm{~kg}^{-1}\right)$ was sprinkled over and mixed through manually before filling the fully mixed substrate into the containers.

Each treatment combination (5 inoculum dilution levels $\times 2$ supplementation levels or 5 inoculum dilution levels $\times 2$ mixing levels) was replicated 4 times, for a total of 40 experimental plots per trial. Plot container dimensions were $52 \mathrm{~cm} \times 40 \mathrm{~cm} \times 25 \mathrm{~cm}$ and contained $18 \mathrm{~kg}$ (fresh weight) of mushroom substrate for Trials 1 and 2, and $16 \mathrm{~kg}$ (fresh weight) of substrate for Trial 3 . Experimental plots were laid out in a randomised block design and incubated under standard mushroom growing conditions at the Teagasc Experimental Mushroom Unit. Mushrooms were harvested and weighed for up to two flushes. Data were analysed by ANOVA. Post hoc comparisons of means were done using Tukey's significant difference test $(P=0.05)$.

Detection and quantification of T. aggressivum propagules in bulk phase III substrate

Detection and quantification of T. aggressivum propagules in each of the four inoculum dilution treatments was carried at the start of Trials 2 and 3 for the heavy mixing treatments only. Sampling of the Phase III substrate was carried out prior to plot filling. For each plot $2 \times 100 \mathrm{~g}$ samples were taken by pooling multiple subsamples of substrate from 10 points distributed across the total mass of substrate. Trichoderma propagule numbers were determined by quantitative polymerase chain reaction (qPCR), weed mould analysis (WMA), most probable number (MPN) determination and direct plating assessment (DPA) as described below. Reverse transcription PCR (RT-PCR) was used to verify the identity of selected Trichoderma cultures from the WMA, MPN and DPA tests. Data from all test results 
were used to calculate the mean and coefficient of variation $(\mathrm{CV})$ for each treatment. Pearson's correlation test with 2-tailed $P$ values and a confidence interval of $95 \%$ was used to test the correlation between inoculum dilution level and the number of T. aggressivum $\mathrm{cfu}^{-1}$ detected for each method. A correlation matrix was also generated to examine the correlation between the different methods.

\section{Quantitative PCR}

One of the $100 \mathrm{~g}$ samples from each plot was sent to the Fera Plant Clinic, York, UK for testing using a qPCRbased test 'Identification of Trichoderma aggressivum from compost' (http://fera.co.uk/agriculturehorticulture/growing/diagnostics/testing-diagnosticservices/mushrooms.cfm). For this test, DNA extraction and qPCR analysis are carried out using $\mathrm{SyBr}$ fluorescence detection and primers targeting the TEF-1 gene sequence (Lane et al. 2010). Results for each sample are given as a 'Cycle Threshold' or CT value.

\section{Weed mould analysis}

Mushroom substrate subsamples (20 g) were mixed with sterile water $(200 \mathrm{ml})$ in a sterile polythene bag and blended using a BagMixer ${ }^{\circledR} 400$ (Interscience) at 100 cycles per minute for $1 \mathrm{~min}$, left stand for $5 \mathrm{~min}$ and mixed again for a further $1 \mathrm{~min}$. The homogenised substrate extract was then serially diluted from $10^{-1}$ $10^{-9}$ in sterile water and $1 \mathrm{ml}$ subsamples were added to plastic Petri dishes in duplicate. A $20 \mathrm{ml}$ aliquot of molten OAES medium (Kaufmann et al. 1963) which had been cooled to $55^{\circ} \mathrm{C}$ was added to the Petri dishes. The extract was mixed with the agar by gentle swirling and allowed to set. OAES plates were incubated for 2 days and Trichoderma colonies were counted on plates showing 20-200 colonies. The plates were reincubated and colonies enumerated after 5-7 days.

\section{Most probably number analysis}

Homogenized substrate extract was prepared as described above and a dilution series was prepared in the range of $10^{-1}-10^{-6}$. Five $10 \mu \mathrm{l}$ drops of diluted extract were spotted onto plates of malt extract agar $(3 \%)$ with $10 \mathrm{ppm}$ streptomycin (MEAS). Plates were incubated for 3 days and each plate was scored for the number of drops showing growth of T. aggressivum. The count was repeated after a further 2 days incubation. The total score was measured for each dilution level and the initial fungal load in the substrate was estimated in terms of cfu $\mathrm{g}^{-1}$ fresh weight by using the most probable number (MPN) method (Halvorson and Ziegler 1933; Briones and Reichardt 1999; Herigstad et al. 2001).

\section{Direct plating assay}

Individual straws were removed from a thoroughly mixed subsample of mushroom substrate and cut to approximately $3 \mathrm{~cm}$ in length using sterilised forceps and scissors. Cut straw pieces (10 per sample) were placed aseptically onto $140 \mathrm{~mm}$ diameter MEAS plates and incubated for 2-4 days. The amount of T. aggressivum in the substrate was scored based on the number of compost pieces (out of 10) from which growth of Trichoderma was observed. The plates were re-incubated and colonies enumerated after 7 days.

\section{RT-PCR verification of T. aggressivum $f$. europaeum}

A number of individual Trichoderma colonies from the WMA, MPN and DPA tests were selected for verification by RT-PCR to ensure that the Trichoderma species isolated were T. aggressivum f. europaeum. Two sets of PCR primer sequences were used: (i) those of Chen et al. (1999), which identify both T. aggressivum f. aggressivum and f. europaeum: Th-F (CGGTGACAT CTGAAAAGTCGTG) and Th-R (TGTCACCCG TTCGGATCATCCG) and produce a 444 base pair product, and (ii) primers designed by Mills (1996), which are specific for T. aggressivum f. europaeum: 18SIntFor (TAACAACACGCCTGCTTAAGA) and Th1IntRev (GAGAAGGCTCAGATAGTAAAAAT) and produce an 802 base pair product.

A GenElute ${ }^{\mathrm{TM}}$ Plant Genomic DNA Miniprep Kit (sigmaaldrich.com) was used to extract DNA from Trichoderma mycelium from solid cultures according to the manufacturer's protocol and using standard molecular biology reagents. Qualitative RT-PCR reactions were carried out in $0.2 \mathrm{ml} \mathrm{PCR}$ tubes with a reaction volume of $12.5 \mu \mathrm{l}$ containing: $6.25 \mu \mathrm{l}$ RedTaq ${ }^{\circledR}$ ReadyMix ${ }^{\mathrm{TM}}$ (sigmaaldrich.com), $1 \mu \mathrm{l}$ forward primer, $1 \mu$ l reverse primer, $2 \mu$ l DNA template and 2.25 $\mu \mathrm{l}$ PCR water. Amplification was carried out in an Eppendorf Mastercycler as follows: lid temperature: $96^{\circ} \mathrm{C}, 95{ }^{\circ} \mathrm{C}$ for 3 min followed by 30 cycles of $95^{\circ} \mathrm{C}$ for $30 \mathrm{~s}, 59^{\circ} \mathrm{C}$ for $30 \mathrm{~s}$ and $72^{\circ} \mathrm{C}$ for 
$1 \mathrm{~min}$. Final amplification was $72{ }^{\circ} \mathrm{C}$ for $10 \mathrm{~min}$. A $10 \mu \mathrm{l}$ aliquot of PCR product per sample was loaded into the wells of $1.5 \%$ agarose gel amended with SYBR®Safe (thermofischer.com) $(1 \mu \mathrm{l}$ per $1 \mathrm{ml}$ agarose gel). Positive and negative controls were included. Electrophoresis was carried out in $1 \mathrm{X}$ TBE buffer (thermofischer.com) at $100 \mathrm{~V}$ for $1 \mathrm{~h}$. The PCR products were visualised, and images captured, using a UVP Bioimaging system.

\section{Results}

Effect of T. aggressivum inoculum and supplementation on mushroom yield from bulk phase III substrate

In Trial 1 the effect of T. aggressivum inoculum and supplementation, in conjunction with low level substrate mixing in a Bulk Phase III system was assessed. The number of $T$. aggressivum propagules in the undiluted inoculum was determined to be $7.15 \times 10^{8} \mathrm{cfu}^{-1}$ by MPN analysis (Table 1). Inoculum dilution level had a highly significant effect on mushroom yield $(P<0.0001)$ with reductions in yield of 40-50\% at the highest level of infection $\left(10^{-1}\right)$ in the first flush which increased to 55$60 \%$ by the second flush (Fig. 1). Supplementation had no significant impact on mushroom yield over two flushes $(P=0.98)$ and there was no significant interaction observed between the two factors $(P=0.33)$.

In Trial 2, the experimental treatments were the same as in Trial 1 but with a higher level of mixing of the substrate and inoculum. The number of T. aggressivum propagules per gram of inoculum in this experiment was determined to be $1.50 \times 10^{9} \mathrm{cfu} \mathrm{g}^{-1}$ by MPN analysis, which was double that of Trial 1 inoculum (Table 1). Yield reductions were more severe in Trial 2 compared to Trial 1, with total crop loss occurring in the first flush for the three highest infection levels (Fig. 2), at which

Table 1 Average number of T. aggressivum propagules in infected substrates used as inoculum in inoculation trials as determined by the MPN method

\begin{tabular}{lll}
\hline $\begin{array}{l}\text { Source } \\
\text { Inoculum }\end{array}$ & $\begin{array}{l}\text { T. aggressivum } \\
\log _{10}(\mathrm{MPN}) \\
\pm \mathrm{st} \text { dev }\end{array}$ & $\begin{array}{l}\text { T. aggressivum } \\
\text { Average cfu g } \\
\text { fresh weight }( \pm \text { st. dev })\end{array}$ \\
\hline Trial 1 $(n=4)$ & $8.854(0.215)$ & $7.15(11.7-4.36) \times 10^{8}$ \\
Trial 2 $(n=4)$ & $9.176(0.414)$ & $1.50(3.89-0.58) \times 10^{9}$ \\
Trial 3 $(n=5)$ & $8.175(0.078)$ & $1.51(2.15-1.05) \times 10^{8}$ \\
\hline
\end{tabular}

— No Supplement $\square$ Supplement

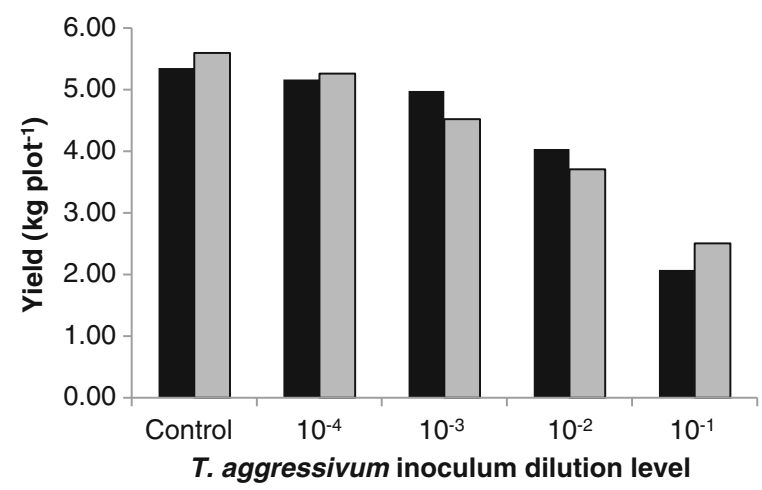

Fig. 1 Effect of T. aggressivum inoculation and substrate supplementation on mushroom yield after two flushes following a low level of Phase III substrate mixing (Trial 1). Data are means of 4 replicates. Tukey's multiple comparison significant difference value $=1.2 \mathrm{~kg}$

time the crop was terminated, but the overall trend was similar. Inoculum dilution level was the only factor to significantly affect the result $(P<0.0001)$. Supplementation had no effect on the mushroom yield after one flush $(P=0.85)$ and there was no significant interaction between the two factors $(P=0.99)$.

Effect of inoculum dilution level and mixing on mushroom yield

In Trial 3 the T. aggressivum inoculum dilution level and degree of substrate mixing treatments were repeated to confirm the effects demonstrated in Trials 1 and 2. The number of T. aggressivum propagules in the inoculum was determined to be $1.51 \times 10^{8} \mathrm{cfu}^{-1}$ by MPN

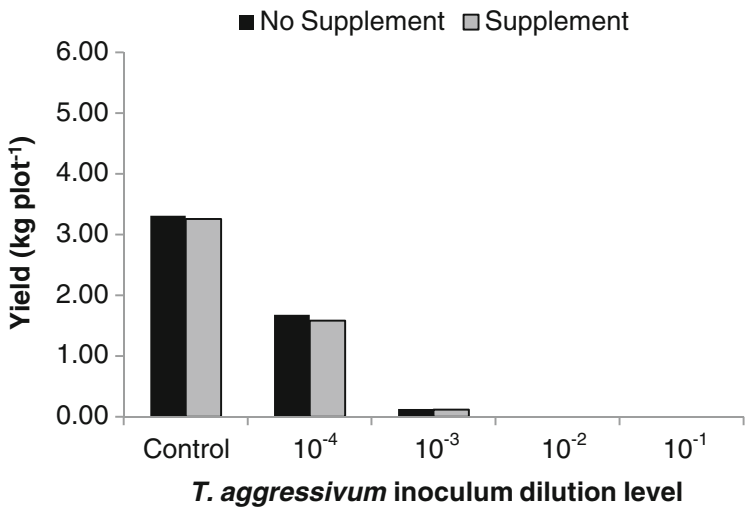

Fig. 2 Effect of T. aggressivum inoculation and substrate supplementation on mushroom yield after one flush following a high level of Phase III substrate mixing (Trial 2). Data are means of 4 replicates. Tukey's multiple comparison significant difference value $=1.3 \mathrm{~kg}$ 
analysis, almost half that of Trial 1 inoculum (Table 1). In Trial 3, both factors significantly affected total yield $(P<0.0001)$ with a significant interaction between the factors $(P=0.004)$ such that the heavy-mix treatment had an increasingly greater impact on yield as the infection level increased (Fig. 3). In the heavy mix treatment, total yield for the two flushes dropped to 54, 10 and $4 \%$ of control, for the $10^{-3}, 10^{-2}$ and $10^{-1}$ infection levels, respectively, while for the light-mix treatments the yields were 96,48 and $36 \%$ of control, for the same infection levels (Fig. 3). A composite image of a representative plot for each treatment combination during the second flush is presented (Fig. 4) and illustrates how the green mould symptoms and crop reduction were more severe in the heavy mix treatment at the higher infection levels. The lowest infection rate $\left(10^{-4}\right)$ had no effect on yield for either mixing treatment but green mould and/or spotting symptoms were evident in most plots during the second flush (Fig. 4).

Comparison of quantification methods

for T. aggressivum in bulk phase III substrate

Four methods for the quantification and detection of T. aggressivum were compared, using sample sets from the heavy mixing treatments of Trials 2 and 3, which best represent commercial bulk handled Phase III substrate. As there was no effect of supplementation, the results from the supplemented and unsupplemented sample sets from Trial 2 were combined. Table 2 shows the means and coefficients of variation of Trichoderma propagule quantification data as determined by qPCR (CT value), MPN (cfu g ${ }^{-1}$ ) and DPA (number of

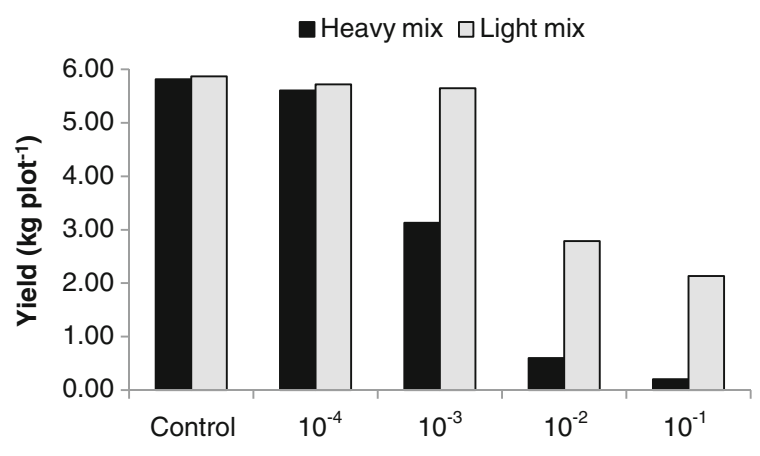

T. aggressivum inoculum dilution level

Fig. 3 Effect of T. aggressivum inoculation and substrate mixing level on mushroom yield after two flushes (Trial 3). Data are means of 4 replicates. Tukey's multiple comparison significant difference value $=1.8 \mathrm{~kg}$ positives out of 10 (Fig. 5a)) from Trial 2 and Trial 3. Due to the time consuming nature of WMA, this method was only performed on the $10^{-2}$ and $10^{-4}$ dilution levels in Trial 2. They were excluded from any correlation analysis but ANOVA showed them to be not significantly different to the MPN results for the same samples $(P=0.11)$. All selected Trichoderma cultures from MPN, WMA and DPA tests which were tested by RTPCR were confirmed as being $T$. aggressivum $\mathrm{f}$. europaeum (Fig. 5b).

Pearson's correlation test showed that there was a significant correlation between the quantity of T. aggressivum propagules detected and the inoculum dilution level for the qPCR, MPN and DPM methods in both experiments (Table 2). A negative correlation was observed for the qPCR analysis because CT value in qPCR analysis is inversely proportional to the amount of T. aggressivum target DNA present in the sample. A correlation matrix was generated to test the similarity of the response of each detection method and is shown in Table 3. For samples from Trial 2, qPCR and DPA results correlated significantly but the results for MPN analysis did not correlate well with either. All detection methods correlated significantly with each other in Trial 3 , indicating that each detection method identified a similar quantitative response to T. aggressivum infection level.

\section{Discussion}

The aim of this work was to assess the impact of T. aggressivum on mushroom yield when a small quantity of infected substrate was mixed throughout a larger volume of uninfected Phase III substrate to reflect what might happen during the bulk handling associated with the emptying and transportation of substrate from Phase III tunnels to farms. The data show that healthy Phase III substrate is vulnerable to infection by T. aggressivum during mixing operations and that the severity of subsequent crop losses is affected by both the relative amount of infected substrate present and how well mixed through the uninfected substrate it is. The addition of a protein-based supplement during the mixing process was shown to have no effect on the severity of T. aggressivum infection although other types of supplements may have different effects.

The severity of the effect of $T$. aggressivum infection on mushroom yield in Trial 2 was greater than in Trial 1 
Fig. 4 Crop surface of representative plots for each treatment from Trial 3 at the start of the second flush

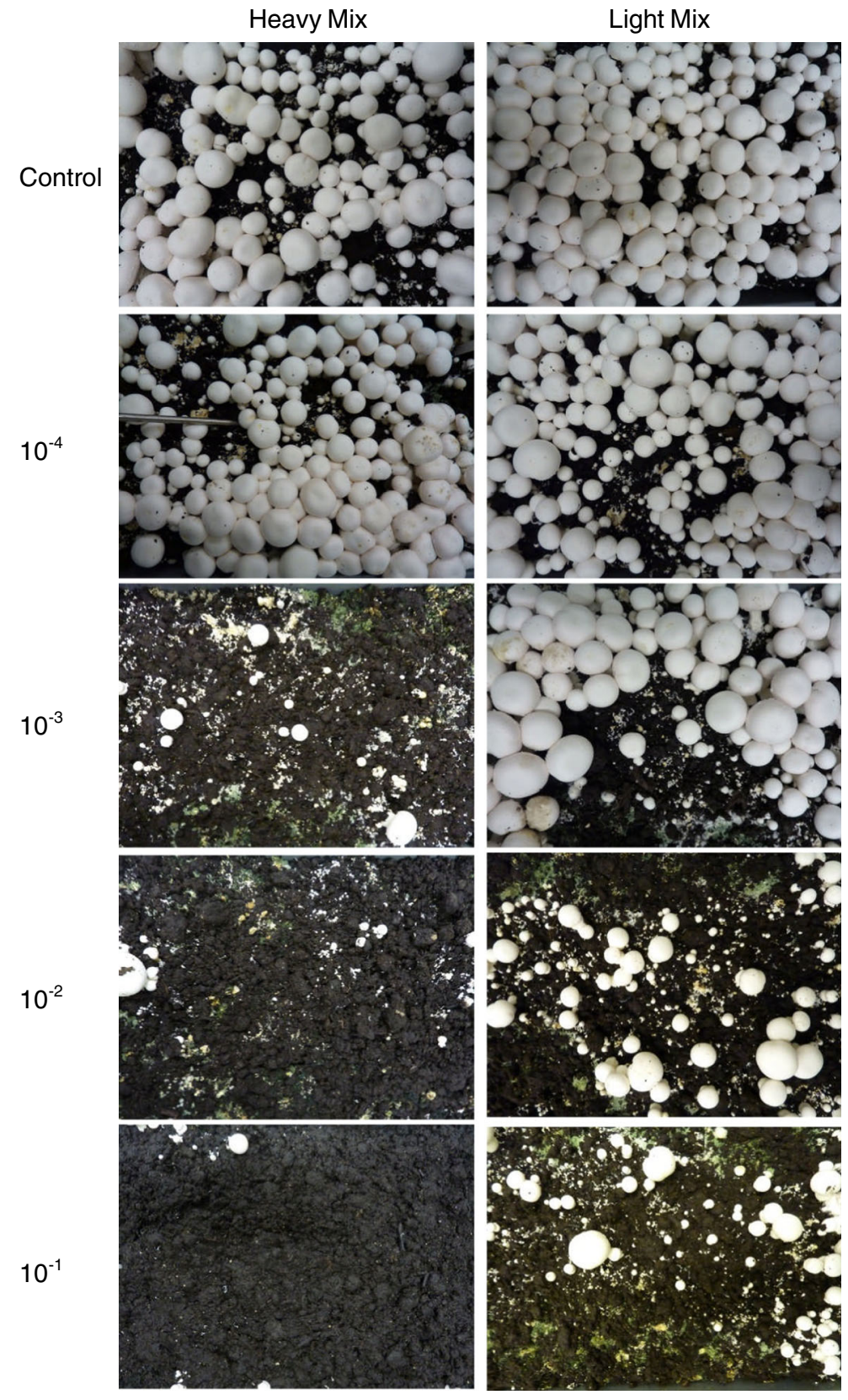

and there are two possible explanations for this. Firstly, the number of $T$. aggressivum propagules per unit weight of inoculum in Trial 2 was double that used in Trial 1 however the reduction in mushroom yield was not proportional; yield loss from the $10^{-4}$ inoculum treatment in Trial 2 was similar to the $10^{-1}$ inoculum treatment in Trial 1 despite having several orders of magnitude less inoculum. Secondly, the manner in which the substrate was mixed was slightly different between the two trials with Trial 1 having a less intensive mixing treatment compared with Trial 2 . The effect of mixing level was evaluated again in Trial 3 and it was shown that more thorough mixing of inoculum with the uninfected substrate resulted in greater crop losses overall. An interaction between the effects of inoculum level and mixing on yield was also observed, indicating that the more dilute the inoculum, the better the yields from the less well mixed treatment. Thus a given amount of 
Table 2 Detection and quantification of T. aggressivum propagules in Phase III mushroom substrate infected with different rates of inoculum and receiving a heavy mixing treatment in Trials 2 and 3. Mixed substrate samples were tested by qPCR, MPN, DPA and WMA methods. WMA tests were done with Trial 2 substrate only. Data are means and coefficient of variation $(\mathrm{CV})$ of 8 replicates (Trial 2) and 4 replicates (Trial 3). Pearson's correlation coefficient $(r)$, the coefficient of determination $\left(r^{2}\right)$ and $P$ value are given

\begin{tabular}{|c|c|c|c|c|c|c|c|c|c|}
\hline & \multirow[t]{2}{*}{ Inoculum dilution level } & \multicolumn{2}{|c|}{ qPCR (CT) } & \multicolumn{2}{|c|}{$\begin{array}{l}\text { MPN } \\
\left(\log \mathrm{cfu} \mathrm{g}^{-1}\right)\end{array}$} & \multicolumn{2}{|c|}{$\begin{array}{l}\mathrm{DPA} \\
(\max =10)\end{array}$} & \multicolumn{2}{|c|}{$\begin{array}{l}\text { WMA } \\
\left(\operatorname{Log~cfu~g}^{-1}\right)\end{array}$} \\
\hline & & Mean & $\mathrm{CV}$ & Mean & $\mathrm{CV}$ & Mean & $\mathrm{CV}$ & Mean & $\mathrm{CV}$ \\
\hline \multicolumn{10}{|l|}{ Trial 2} \\
\hline & $10^{-1}$ & 24 & 0.04 & 6.2 & 0.03 & 9.4 & 0.14 & $-^{a}$ & \\
\hline & $10^{-2}$ & 27 & 0.03 & 4.8 & 0.15 & 6.8 & 0.42 & 4.3 & 0.28 \\
\hline & $10^{-3}$ & 29 & 0.04 & 0.8 & 0.58 & 6.8 & 0.22 & - & \\
\hline & $10^{-4}$ & 35 & 0.02 & 0 & 0 & 1.7 & 0.61 & 0.1 & 0.58 \\
\hline & Control & 40 & 0 & 0 & 0 & 0 & 0 & - & \\
\hline$r$ & & -0.98 & & 0.94 & & 0.96 & & & \\
\hline$r^{2}$ & & 0.97 & & 0.88 & & 0.92 & & & \\
\hline$P$ value & & 0.002 & & 0.018 & & 0.009 & & & \\
\hline \multicolumn{10}{|l|}{ Trial 3} \\
\hline & $10^{-1}$ & 28 & 0.06 & 6.52 & 0.11 & 9.5 & 0.06 & - & \\
\hline & $10^{-2}$ & 32 & 0.05 & 3.04 & 0.75 & 7.5 & 0.44 & - & \\
\hline & $10^{-3}$ & 37 & 0.09 & 2.55 & 0.2 & 2.5 & 0.52 & - & \\
\hline & $10^{-4}$ & 40 & 0 & 0 & 0 & 0.25 & 2 & - & \\
\hline & Control & 40 & 0 & 0 & 0 & 0 & 0 & - & \\
\hline$r$ & & -0.95 & & 0.95 & & 0.96 & & & \\
\hline$r^{2}$ & & 0.90 & & 0.89 & & 0.92 & & & \\
\hline$P$ value & & 0.014 & & 0.015 & & 0.009 & & & \\
\hline
\end{tabular}

$\mathrm{a}-=$ Not tested

infection will have a far greater impact within the Bulk Phase III system than if it occurred in an in-situ cropping system. The lowest level of inoculum in Trial $3\left(10^{-4}\right)$ had no impact on yield after two flushes, irrespective of the level of mixing however, surface green mould symptoms were observed more consistently in the heavily mixed plots compared with the lighter mixed plots
(Fig. 4). It is likely therefore that yields from the heavily mixed $10^{-4}$ plots would have suffered in the third flush. Only the DPA detection method identified T. aggressivum in the mixed substrate for the $10^{-4}$ inoculum treatment in Trial 3 suggesting that this inoculum level was close to the limit of detection. Thus T. aggressivum is likely to go undetected on farms and
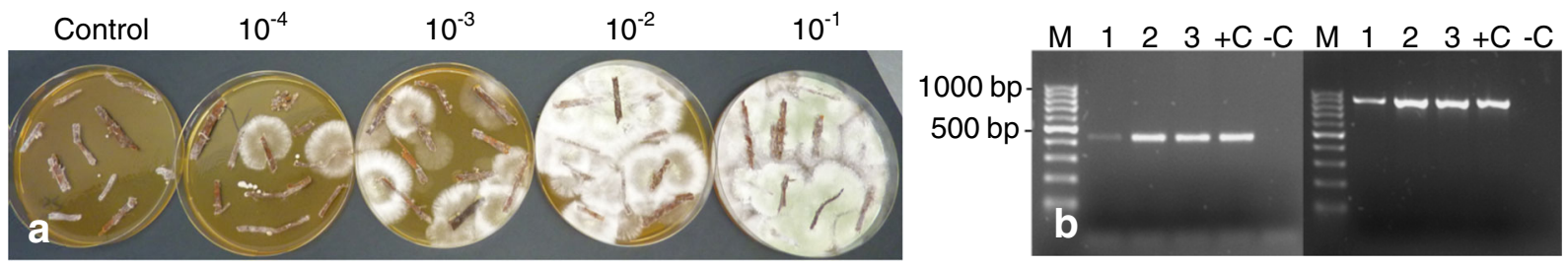

Fig. 5 (a) Trichoderma aggressivum detection in Phase III substrate using the direct plating assessment of 10 compost fragments per treatment following substrate inoculation with different rates of inoculum (one set of replicates from Trial 2); (b) PCR confirmation of T. aggressivum f. europaeum for selected isolates from
WMA, MPN and DPA tests. M = 100 bp marker ladder; $1-$ 3 = isolate number; $+\mathrm{C}=+$ ve control; $-\mathrm{C}=-\mathrm{ve}$ control. Left hand gel: 444 bp PCR product using Chen et al. (1999) primers; right hand gel: 820 bp PCR product using Mills (1996) primers 
Table 3 Pearson Correlation analysis ( $\mathrm{R}$ value) and significance level between different methods for the detection of T. aggressivum in mushroom substrate used in Trial 2 and Trial 3 ; ns = not significant; $*=P<0.05 ; * *=P<0.01$

\begin{tabular}{lllll}
\hline & & \multicolumn{3}{l}{ Pearson R value } \\
\cline { 4 - 5 } & Detection method: & qPCR & MPN & DPA \\
\hline Trial 2: & & & & \\
& qPCR & 1 & & \\
& MPN & & & \\
Trial 3: & DPA & $-0.87 \mathrm{~ns}$ & 1 & \\
& & $-0.98 * *$ & $0.82 \mathrm{~ns}$ & 1 \\
& qPCR & & & \\
& MPN & 1 & & \\
& DPA & $-0.96 * *$ & 1 & \\
\hline
\end{tabular}

substrate facilities where very low levels of T. aggressivum are present and having little impact on yield. This will allow a build-up of inoculum potential over time to a point when the inoculum is high enough to be reflected in reduced performance of the substrate.

A possible explanation for the more severe impact of T. aggressivum within the heavily mixed Bulk Phase III system may be that the disruption of spawn-run substrate puts A. bisporus under stress. Fully spawn run substrate is generally considered to be robust and less susceptible to diseases and moulds, including T. aggressivum, due to the strong binding action and universal presence of an integrated tightly-woven A. bisporus mycelial network throughout the substrate mass (Seaby 1987; Rinker 1997). However, when Phase III substrate is bulk handled during tunnel emptying, the tightly bound and semi-solid substrate is broken up, becoming friable, rupturing the fragile A. bisporus mycelial network in the process. This disruption may present a new food source for T. aggressivum, through the release of cellular nutrients which are not accessible when the fully colonised substrate is intact. Extracts from $A$. bisporus have been shown to have a stimulatory effect on the growth of T. aggressivum (Mumpuni et al. 1998) and spores of T. aggressivum are known to germinate in the presence of $A$. bisporus, where other Trichoderma species are inhibited (Mamoun et al. 2000b). Thus, the rupturing of the A. bisporus mycelial network during bulk handling, along with the release of nutrients and stimulatory metabolites, is likely to provide an ideal opportunity for T. aggressivum propagules to colonise what has become a more accessible substrate. Further work is in progress to assess this effect within a model Bulk Phase III tunnel system.

The four methods for the detection and/or enumeration of T. aggressivum propagules in mushroom substrate that were compared gave results that showed a significant correlation between the inoculum level and the quantity of $T$. aggressivum detected. Of the two microbiological counting methods (MPN and WMA) there was no significant difference in their ability to enumerate $T$. aggressivum in substrate $(P=0.11)$. The MPN method is widely used as an alternative to traditional colony counting methods (Garthright and Blodgett 2003) and based on these data it was found to be a time-saving alternative to full weed mould analysis. However, both methods returned false negative results at lower infection rates and displayed increases in the coefficient of variation as the inoculum level in the infected substrate was diluted.

The direct plating assay (DPA) was a very simple method of determining the presence or absence of T. aggressivum in bulk handled Phase III samples and also gave an indication of the concentration of infection (Fig. 5) with the number of pieces of substrate showing growth of $T$. aggressivum being significantly correlated $(P=0.009)$ to the inoculum dilution rate (Table 2$)$. However, the coefficient of variation for this test also increased with increased dilution levels, similar to the other two growth-dependent detection methods. The DPA method had the lowest number of false negative results of those tested and was the only method to detect T. aggressivum at the lowest level of infection in Trial 3, in one of four samples tested. However T. aggressivum had developed in three out of the four replicate plots by the second flush so that it is likely that false negatives were also recorded by the DPA method for the substrates from two of the replicates. Considering these factors the direct plating assay represents an attractive and simple option for the detection of Trichoderma in bulk handled Phase III substrate when enumeration is not essential. However, any Trichoderma-positives will have to be identified further by RT-PCR to determine if they are T. aggressivum or not.

Quantitative PCR was the most technologically advanced method used to enumerate T. aggressivum in this study. In these experiments this method was more sensitive than the two microbiological counting methods and could detect $T$. aggressivum in the substrate where the inoculum was diluted to $10^{-4}$ level in Trial 2, but it 
returned negative results at this inoculum dilution in Trial 3, where the amount of T. aggressivum in the source inoculum was an order of magnitude lower (Table 1). The problem of increasing variation with increasing dilution level was not observed with qPCR; the coefficient of variation remained largely constant, regardless of the dilution level. Quantitative PCR is the fastest method as results can be obtained on the day of processing, providing the expertise and equipment is available. Where a commercial service is used, there will be delays due to sample transportation and sample turn-around time of the service provider, as well as cost. However, unlike culture dependent methods the qPCR method does not distinguish between viable and nonviable cells and this should be taken into account when interpreting results.

The most significant challenge to the accurate enumeration of T. aggressivum in Bulk Phase III substrate is sampling. Representative sampling is key to the determination of the concentration of a given species within a population without sampling the entire population. That is to say, if a sample is taken from any mass of material and subjected to a test the measurement thereby obtained is only true for the sample tested, and in order to extrapolate the measurement to the whole mass it is necessary to assume that the sample contains the exact same constituent as the whole mass, in the same proportions (Petersen et al. 2004). This assumption is key to using a destructive sampling technique, like those used above, because it is not possible to sample the whole population. The assumption that a sample is representative of the whole is usually valid for liquids since they can be mixed effectively to produce homogeneous solutions. Thus, for many biological assays the contribution of sampling error to total error is minimal because the material tested is naturally homogenous (Esbensen and Heydorn 2004). Mushroom substrate is a solid composed of large, irregularly shaped particles which makes attaining a representative sample by mixing much more difficult (Petersen et al. 2005). Each method of T. aggressivum enumeration other than qPCR showed increasing variability with increased inoculum dilution level, which suggests that the T. aggressivum was not evenly distributed in the substrate after mixing, giving rise to more variable results with increasing dilution. The low variability at high dilution levels of the qPCR results may be due, in part, to the methodology used where a liquid extract was obtained from $75 \mathrm{~g}$ of substrate from an initial $100 \mathrm{~g}$ sample, which was then tested by qPCR (Lane et al. 2010). For MPN and WMA methods, liquid extracts were prepared from $20 \mathrm{~g}$ samples from an initial $100 \mathrm{~g}$ sample. Thus the larger sub-sample size used to prepare the liquid extract for qRCR testing is likely to have improved the reliability of that method compared with the smaller subsample size used in the MPN and WMA methods, even though both $100 \mathrm{~g}$ samples were taken at the same time. Although it was the least variable method, qPCR did not detect T. aggressivum in the $10^{-4}$ inoculum dilution level in Trial 3, even though the mean propagule load in the substrate was calculated to be in the order of $10 \mathrm{cfu} \mathrm{g}^{-1}$ and the DPA method gave a positive result. This is likely due to a combination of factors including the non-homogenous distribution of T. aggressivum infected substrate during the mixing process, resulting in differences between samples, as well as reaching the limit of detection.

In conclusion, T. aggressivum infections can spread from fragments of infected substrate when they are diluted into a larger volume of clean A. bisporus substrate, during the mixing processes associated with the bulk handling of fully colonized Phase III. This is an important piece of epidemiological information as fully spawn-run substrate was previously considered to be resistant to infection by $T$. aggressivum. These results suggest a new avenue of contamination where small localized pockets of infected substrate at the bulk incubation stage can be diluted throughout otherwise uninfected Phase III substrate during bulk handling. Localised patches of infected substrate can harbour different levels of T. aggressivum propagules $\left(\mathrm{cfu} \mathrm{g}^{-1}\right.$ ) and this will affect the subsequent impact on the crop when it is diluted through the substrate. Thus, the more heavily colonized an area of infected substrate is, the greater the impact it will have on the subsequent crop, compared to an infected substrate with a low count of $T$. aggressivum $\mathrm{cfu}^{-1}$, which may not manifest any crop loss or green mould symptoms. A variety of detection methods successfully detected T. aggressivum propagules up to an inoculum dilution level of $10^{-4}$. A qPCR method of detection and quantification was effective and consistent over a range of inoculum dilutions although false negatives are possible in the most dilute samples. A simple DPA method could provide an early warning system to the presence of Trichoderma in a sample of Phase III but would require confirmation of species identification by PCR. 
Acknowledgments M. O'Brien was the recipient of a Teagasc Walsh Fellowship. Part of this work was funded by the Agriculture and Horticultural Development Board, Stoneleigh Park, Warwickshire, UK. Brian McGuinness provided technical assistance with crop trials and RT-PCR.

\section{References}

Anon. (2016a). MushComb Flexible New Machinery. http://issuu. com/willigendael/docs/mush comb brochure

Anon. (2016b). Hoving Holland Int. BV. Mushroom and composting equipment. http://www.hovingholland.com/ muschroom-culture-machinery-manufacturer-treatmentcultivation

Beyer, D. M., Wuest, P. J., \& Kremser, J. J. (2000). Evaluation of epidemiological factors and mushroom substrate characteristics influencing the occurrence and development of Trichoderma green mold. Mushroom Science, 15(2), 633640.

Briones Jr., M. A., \& Reichardt, W. (1999). Estimating microbial population counts by most probable number using Microsoft excel®. Journal of Microbiological Methods, 35, 157-161.

Chen, X., Romaine, C. P., Ospina-Giraldo, M. D., \& Royse, D. J. (1999). A polymerase chain reaction-based test for the identification of Trichoderma harzianum biotypes 2 and 4, responsible for the worldwide green mold epidemic in cultivated Agaricus bisporus. Applied Microbiology and Biotechnology, 52(2), 246-250.

Esbensen, K. H., \& Heydorn, K. (2004). Metrology in sampling, a first foray (biological materials). Chemometrics and Intelligent Laboratory Systems, 74(1), 115-120.

Fletcher, J. T. (1997). Mushroom spawn and the development of Trichoderma harzianum compost mold. Mushroom News, 45(8), 6-8.

Fletcher, J. T., \& Gaze, R. H. (2008). Mushroom Pest and disease control. London, UK: Manson Publishing.

Garthright, W. E., \& Blodgett, R. J. (2003). FDAs preferred MPN methods for standard, large or unusual tests, with a spreadsheet. Food Microbiology, 20, 439-445.

Grogan, H. M., Noble, R., Gaze, R. H., \& Fletcher, J. T. (1996). Control of Trichoderma harzianum - a weed mould of the cultivated mushroom. Brighton Crop Protection - Pests \& Diseases, 4(B-3), 337-343.

Halvorson, H. O., \& Ziegler, N. R. (1933). Application of statistics to problems in bacteriology I. A means of determining bacterial population by the dilution method. Journal of Bacteriology, 25(2), 101-121.

Herigstad, B., Hamilton, M., \& Heersink, J. (2001). How to optimize the drop plate method for enumerating bacteria. Journal of Microbiological Methods, 44(2), 121-129.

Kaufmann, D. D., Williams, L. E., \& Summers, C. B. (1963). Effect of plating medium and incubation temperature on growth of fungi in soil-dilution plates. Canadian Journal of Microbiology, 9(6), 741-751.

Lane, C., Nixon, T., Woodhall, J., Glover, R., O’Brien, M. \& Grogan, H. (2010). Trichoderma green mould-Diagnostic assays for improved disease management. 20p. HDC Report M48. Agriculture and Horticulture Development Board, Stoneleigh Park, Kenilworth, CV8 2TL, UK.

Largeteau, M. L., Latapy, C., Minvielle, N., Regnault-Roger, C., \& Savoie, J.-M. (2010). Microbially induced diseases of Agaricus bisporus: biochemical mechanisms and impact on commercial mushroom production. Applied and Environmental Microbiology, 158, 69-83.

Lemmers, G. (2010). Trichoderma in bulk phase III (part 1). Mushroom Business, 40, 10-13.

Mamoun, M. L., Savoie, J.-M., \& Olivier, J.-M. (2000b). Interactions between the pathogen Trichoderma harzianum Th2 and Agaricus bisporus in mushroom compost. Mycologia, 92, 233-240.

Mills, P. (1996). Development of a rapid diagnostic test for colonising forms of Trichoderma. 22p. HDC Report M 10a. Agriculture and Horticulture Development Board, Stoneleigh Park, Kenilworth, CV8 2TL, UK.

Mumpuni, A., Sharma, H. S. S., \& Brown, A. E. (1998). Effect of metabolites produced by Trichoderma harzianum biotypes and Agaricus bisporus on their respective growth radii in culture. Applied and Environmental Microbiology, 64(12), 5053-5056.

Petersen, L., Dahl, C. K., \& Esbensen, K. H. (2004). Representative mass reduction in sampling: a critical survey of techniques and hardware. Chemometrics and Intelligent Laboratory Systems, 74(1), 95-114.

Petersen, L., Minkkinen, P., \& Esbensen, K. H. (2005). Representative sampling for reliable data analysis: theory of sampling. Chemometrics and Intelligent Laboratory Systems, 77(1-2), 261-277.

Rinker, D.L. (1997). Sensitivity of spawn-run compost or casing to green mould infection. Mushroom World, 44-47

Rinker, D. L., \& Alm, G. (2000). Management of green mould disease in Canada. Mushroom Science, 15(2), 617-623.

Rinker, D. L., \& Alm, G. (2008). Management of casing Trichoderma using fungicides. Mushroom Science, 17, 496-509.

Romaine, C. P., Royse, D. J., \& Schlagnhaufer, C. (2008). Emergence of benzimidazole-resistant green mould, Trichoderma aggressivum, on cultivated Agaricus bisporus in North America. Mushroom Science, 17, 510-523.

Samuels, G. J., Dodd, S. L., Gams, W., Castlebury, L. A., \& Petrini, O. (2002). Trichoderma species associated with the green mold epidemic of commercially grown Agaricus bisporus. Mycologia, 94, 147-170.

Seaby, D. A. (1987). Infection of mushroom compost by Trichoderma species. Mushroom Journal, 179, 355-361.

Seaby, D. A. (1996). Investigation of the epidemiology of green mould disease of mushroom (Agaricus bisporus) compost caused by Trichoderma harzianum. Plant Pathology, 45, 913-923. 